\title{
Ethno-cultural identity as a form of social homeostasis
}

\author{
Krasimir ASENOV ${ }^{1}$ \\ ${ }^{1}$ Plovdiv, Bulgaria \\ ORCID: 0000-0002-3213-6063
}

\section{ABSTRACT}

Homeostasis describes the ability of organisms to maintain a relatively stable internal state. Recently, this term come to be used by scientists working in several scientific fields. For instance, environmentalists apply the principle of homeostasis to their understanding of the global environment wherein modern civilization is developing. Homeostasis is now used in various fields such as cybernetics, psychology, and the social sciences.

As open systems, human communities exhibit general states that can be recognized as forms of a social homeostasis. Maintaining positive demographic growth, resistance to acculturation processes, balanced migration, manifestations of preferred identity phenomena, high levels of intra-community control, and high levels of gray economy involvement are only part of the mechanisms through which social homeostasis functions.

Keywords: Social homeostasis, Ethno-cultural identity, Millet, Turks, Roma, Bulgaria. 


\section{INTRODUCTION}

In the creation of the current theory of social homeostasis, field studies of the Millet community of the city of Plovdiv, Bulgaria, were performed, mainly in Harman Mahala quarter and the other ghettoized urban structures ${ }^{1}$ of the city, such as Stolipinovo, Sheker Mahala and Hadji Hasan Mahala. In addition, partial studies of the existing ghettoized urban structures in other cities across Bulgaria, such as Asenovgrad, Pazardzhik, Burgas, Varna, Stara Zagora and Haskovo, have also been done. All these ethnic areas are part of the so-called invisible or hidden urban geography. Although the research is based on a limited geographic area, other communities would also fit into the concept of the suggested theoretical framework.

The majority of the population in these locally segregated communities use the endonym Millet as their ethnic marker, which is often used together (or separately), with the endonym Turkish. Although the process of forming a unified Millet community in the country is not yet complete, we can assume that the above-listed ethnic areas are populated by representatives of one and the same ethno-cultural community. Regardless of the autonyms which that community identifies itself with, the surrounding population regards that same community as the largest Roma / Gypsy group in Bulgaria, referring to its representatives as Horohane Roma, Turkish Gypsies, Yerlii, etc.

After years of research into the habitat and the ethno-cultural characteristics of the community ${ }^{2}$, it can be said that its main characterizing markers are its adaptability and vitality. The adaptation of the community to an ever-changing environment and the preservation of ethnocultural identity are all processes that strongly resemble the process of homeostasis.

\section{ESSENCE OF THE HOMEOSTASIS}

Among the many significant achievements of the French physiologist Claude Bernard (1813-1878) - one of the first to propose the use of blind experiments to guarantee the objectivity of scientific observations - is also the introduction of the term milieu intérieur (meaning in French language - internal environment) in 1865. As early as 1857, Bernard thought that a permanent internal environment was a prerequisite for the normal existence of any living organism. Bernard is also the author of the postulate stating that: Persistence of the interior environment is the key to a free and independent life (Gorizontov, 1981). The term homeostasis itself was first introduced to scientific circulation by the American physiologist Walter Bradford Cannon (Cannon, 1926) who was the one to formulate the definition of homeostasis. The concept of homeostasis Cannon understands as a sum of physiological parameters which determine the steadiness of the internal environment. Such parameters are: the body temperature, the blood composition, the blood pressure, the metabolic processes, etc.

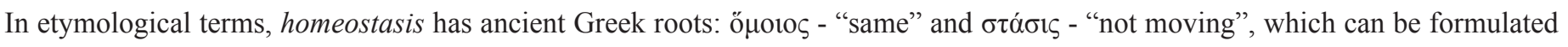
as "remaining the same." In that same source homeostasis is defined as a relatively stable state of equilibrium or a tendency for such a state between different but interdependent elements or groups of elements of an organism, population, or a group (Merriam-Webster Dictionary).

\section{FROM HOMEOSTASIS TO SOCIAL HOMEOSTASIS}

The principles of regulation of biological processes that exist in organisms resemble the principles of control observed in inanimate systems, such as machines - in both cases the stability of the system is achieved through a certain form of control. In 1948, the American mathematician Norbert Wiener proposed the science that studies the common models of control and transfer of information in machines, living organisms, and societies to be called cybernetics (from Greek $\kappa v \beta \varepsilon \rho v \eta \tau \iota \xi \dot{-}$ - meaning management, governance). By the definition of Berg (1962), cybernetics means the science of purposeful and optimal management of complex processes occurring in wildlife, in human society or in industry. Cybernetics deals with the establishment of the laws governing one process or another, whether they originate in living nature or in inanimate systems. Cybernetics is an interdisciplinary science that is formed at the crossroads of mathematics, logic, semiotics (science of signs), physiology, biology and sociology. From the perspective of cybernetics, all forms of wildlife are considered open, self-regulating and integrated systems, capable of maintaining structural and functional stability (homeostasis) under changing

1 The lack of a universal definition of ghetto poses serious limitations to the free use of that term. Its polysemantic character predefines my choice that the ethnicallyformed quarters in the city of Plovdiv be referred to as ghettoized urban structures (GUS).

2 Further in the text, the usage of "community" concerns the studied ethno-cultural community, unless pointed out otherwise. 
conditions of existence. The mechanisms for ensuring such stability are very diverse and fixed over the course of a long evolution at the genetic level. Those mechanisms are aimed at the formation of various forms of adaptation at all levels of the organization of living systems: molecular, cellular, tissue-organic, organic and supra-organismal (population-species, biogeocenotic and biospheric). Every living system and organism as such are open systems that exchange substances, energy and information with the external environment. In accordance with environmental signals, organisms respond to them in one way or another, which in fact also ensures the permanence of the internal environment, i.e. homeostasis (Gevandova et al. (2017).

Assuming that every human being is considered an open, self-regulating and integral system, capable of maintaining structural and functional stability (homeostasis) under changing conditions of existence, then any organized set of human beings is a collective body at the social level (community). Of course, the degree of openness of different communities varies and depends on many factors: the ethnocultural characteristics of the communities themselves; the degree of external impact - the geographical abiotic and biotic features of their habitat, including the anthropogenic impact, etc. In this aspect, it is difficult to compare the internal and external conditions that affect the degree of openness of individual communities, for example: the Yazidis (Yazides, Yazidis), the Basques, the Bosha (Lom), the Ainu, the Noatak Inuits, the Tlakluit (Wishram) Indians, etc. Each has its own culture, and culture is an identifier, a phenomenon that characterizes each community, creating that specific embossing on the pages of history that makes it visible and unique (Asenov, 2018). And so each of these communities builds combinations of their own mechanisms that determine the functioning of their social homeostasis. This continues until social homeostasis is completely disorganized or compromised, leading in the first case to serious functional disorders in the collective body, and in the second - to the death of the collective body or a complete ethno-cultural assimilation of the community. Due to the importance of this process, we will put some more emphasis on it. At each level, homeostasis is different. It can be said that any disturbance in the mechanisms of homeostasis, manifests itself in the organisms as a state of disease. In cases of disturbances of biosphere homeostasis - environmental crises arise, while in cases of irreversible disturbances - an environmental catastrophe occurs. In case of disturbances in the process of social homeostasis, however, the community begins to lose its characteristic ethno-cultural markers and falls into a process of acculturation. When that community loses its ability to resist any external and internal processes which lead to the loss of the ethnical characteristics of its cultural matrix, that community ceases to exist. It is easy to find examples in historiography, not only for communities, tribes, peoples, but also for entire civilizations whose social homeostasis was compromised to the extent that they permanently lost their ethno-cultural identity and ceased to exist. Here we can mention many Native American tribes that have already gone extinct, as well as the Eurasian peoples of the Cumans, Alans, Huns, the Ancient Sumerians, the Ancient Egyptians, the Achaeans, the Thracians, etc., the South American Olmecs, Aztecs, Toltecs, Zapotecs, Mayans, etc., the Harappan Civilization (its borders included territories of present-day Iran, India, Pakistan and Afghanistan), the Angkor civilization in Cambodia, the civilization of the Nabta Playa valley, in the East Sahara desert, and so forth. This list can be extended a lot, but what those peoples had in common was that at a certain historical moment their social homeostasis ceased to function, which also lead to their disappearance from the world historical stage. However, that does not automatically mean that they also ceased their physical existence. Usually, in such cases, those communities (tribes, peoples, civilizations) melt into other communities whose social homeostasis is "alive", or in other cases - such extinct communities served as a basis for the formation of new ethnic communities.

\section{ESSENCE OF THE SOCIAL HOMEOSTASIS}

So what is social homeostasis? A social phenomenon or an evolutionarily-based instinct of the collective body, a community immune system, or a function of natural selection? Social homeostasis is a collection of regulatory mechanisms that provide an optimal environment for the ethno-cultural development of the collective body (in this case, the community). This is achieved through numerous dynamic equilibrium adjustments driven by interconnected regulatory mechanisms. It can also be said that: social homeostasis is the tendency of a collective body, through a system of measures and mechanisms, to oppose, ignore or tolerate external and internal changes, the ultimate goal being to maintain an optimal environment for the development of the ethno-cultural identity of the community.

Another, not so orthodox, discourse about the positive role of social homeostasis, claims that the desire for homeostasis is not a characteristic of a normal organism, but a sign of pathology (Aranovskiy, 2002). Of course, this reading of the role of social homeostasis is not entirely deprived of logic: social pathology is required to activate the homeostasis process (or the social homeostasis process as in this case). For example, in order to activate the social homeostasis concerning the ethno-cultural survival of the Bulgarian ethnic community, a social pathology emerges - a demographic crisis (taking the proportions of a demographic catastrophe) - a severe decrease in the 
population number of the Bulgarian ethnic group. The natural decrease of the population of Bulgaria is not only a consequence of the higher number of deaths compared to the number of live births, but also of the effects other domestic factors have - socio-economic, political, psychological, etc. - leading to atypically high values of emigration. In that case, if the social homeostasis of the Bulgarian ethnic group is functional, it will eliminate the agents (causes) that bring the system out of balance. Unfortunately, the values of the demographic indicators according to international and national studies are not encouraging - Bulgaria's population is declining faster than that of any other nation in the world (Kotecki, 2018). The latter study also indicates that the population of Bulgaria - the poorest member of the European Union - may soon become as small as it was right after World War II. It is expected to reach just 5.4 million by 2050. As of 2017, the population of the country was estimated at around 7 million people. In addition, there is an increase in emigration as citizens seek employment elsewhere. The total fertility rate in Bulgaria is only 1.46 children per woman. "The decline of the active population is a social and economic bomb that will explode if we do not take adequate measures", Bulgarian Deputy Labor Minister Sultanka Petrova declared for Bloomberg last year.

Despite the government's willingness to take action to prevent the demographic catastrophe, no serious action has been taken. This is a classic case of illustration of a compromised social homeostasis.

Of course, when we talk about different ethno-cultural communities, it is necessary to note that the social homeostasis of each society functions under different algorithms and mechanisms. While for the Bulgarian ethnic group the most serious problem is the demographic collapse, there are ethnic communities within the same country (such as the Roma and the ethnic Turks), which do not have this problem.

Although, since the democratic changes in Bulgaria (following 1989), the birth rate among the studied Millet community has been steadily declining, it remains within the stable 2.2 children per woman - a prerequisite for natural growth of the population. This is a good illustration of the impact of the same factor (the demographic crisis), within the same chronotope, on two different ethno-cultural communities, and the way their social homeostasis functions.

As it was mentioned earlier, social homeostasis affects the factors that try to destabilize the community system by seeking to neutralize their negative impact on the community. The factors can be classified as external and internal. As external factors affecting the studied community we can identify the following: the impact of acculturation processes; social, spatial, infrastructural, institutional and other types of discrimination; the impact of globalization and modern technologies, etc. As internal factors we can identify the high emigration levels (mainly to Western Europe); persistent tendencies towards declining birth rates (the total fertility rate in the 1980s was around 2.80, as opposed to the current levels of around 2.2); high levels of unemployment and low education level; a trend of increasing levels of exogamous marriages; rejection of the national education system; unsatisfactory health condition; significantly shorter life expectancy (the average life expectancy of the surveyed community is about 8 years shorter than that of ethnic Bulgarians, and about 13 years shorter compared to the Western European population); dissemination of non-traditional confessional practices; lack of health insurance (nearly half of the members of the studied community have no health insurance, while one in five never had one); diminishing intensity of family ties, etc.

Below are some specific factors that affect the community in discussion and the respective reaction of its social homeostasis:

a) Decreasing birth rates.

Despite the positive demographic growth, there is a steady trend of declining birth rates in the community. What are the mechanisms of social homeostasis that limit this process? Social homeostasis uses the community's ethno-cultural matrix to construct mechanisms that limit the decrease of birth rates. Here are some of those mechanisms: a strong refusal to use contraceptives; encouragement of young families to increase fertility; if the first and second child in the family happen to be female, then the woman is more likely to have a third child, hoping it is a male child. Sometimes this process can continue until the fourth or the fifth child (during fieldwork in Harman Mahala, Plovdiv, we came across a case in which, hoping for a male child a woman had given gave birth to 6 girls); another important ethnopsychological feature which manifests itself as a social homeostasis mechanism promoting birth rates in the community is associated with high levels of family and social support - a child should not be left alone but rather have siblings for support when the parents die; due to the high infant mortality rate in the community in the past (the infant mortality rate is even now 25.0 per 1000 live births, compared to 9.9 for the Bulgarian community, (NSI, 2001). Therefore, we assume that high birth rates are the natural mechanism of social homeostasis to maintain the positive demographic growth of the community. 
b) Low levels of attained education - high levels of unemployment.

The two factors - education and unemployment - are inversely dependent and this rule is explicitly manifested within the surveyed community. More than $8 \%$ of women and $12 \%$ of men are without any education. Some $54 \%$ of women and $43 \%$ of men only attended school till reaching fourth grade. Almost $29 \%$ of women and $25 \%$ of men attended school till seventh grade. Secondary education (highschool level) has been attained by a mere $2 \%$ of women and $9 \%$ of men. Members of the community with a higher education constitute below $0.5 \%$ (Author's field study of Harman Mahala quarter, Plovdiv). These education levels also predetermine, to a great extent, both the economic sectors and the type of work that the members of the community can do - low-skilled and not well-paid jobs. At the end of the last century, the level of the community unemployment rates reached a whopping 80-90\%. A large part of the people became involved in the grey economy: "suitcase trade", illegal production and trade of excise goods, "sidewalk trade", etc. After Bulgaria's accession to the $\mathrm{EU}$, the strategy changed and a process of chain migration to the economically prosperous Western part of the continent began. To our question "Why are you migrating to Western Europe?", we received the following answer: In both Bulgaria and Germany we do the hardest and the dirtiest work, but in Germany we get paid 4-5 times more. Our children speak German and will live better than us. We sacrifice ourselves for them because in Bulgaria - regardless of whether we study or not-it's all the same-nobody employs us anyway.

The deep problem of low education level and functional illiteracy among the members of the community is due to complex factors, some of which were already mentioned: the lack of an integrated education system in the country, suitable for bilingual children; the existence of entirely segregated schools which almost all children of the community go to; low educational attainment in segregated schools; the presence of ethno-cultural features that reflect on the school dropout rates, etc.

Through what mechanisms does the community's social homeostasis compensate for the lack of good education among the community members? Here are some of them: working in the grey economy sector; mass practice of informal and unregulated trading activities; labor emigration, etc. All that is clearly illustrated by Figure 1 which shows the structure of a household income in Harman Mahala quarter, Plovdiv, where the vast majority of the population declares itself as Millet.

\section{REFERENCES}

Aranovskiy, K. (2002). Mythology and worldview in relation to state legal regulation. Journal of Russian Law, № 9, pp. 84-92 (in Russian)

Asenov, K. (2018). Anthropology of the "ghetto" - space and culture, "Studio 18", Plovdiv (in Bulgarian)

Berg, A. et al. (1962). Cybernetics. Philosophic encyclopedia, Vol. 2, Moscow (in Russian)

Cannon, W. B. (1926). „Physiological regulation of normal states: some tentative postulates concerning biological homeostatics“. B A. Pettit(ed.).

A Charles Richet: ses amis, ses collègues, ses élèves (in French). Paris: Les Éditions Médicales. p. 91.

Gevandova et al. (2017). Homeostasis of the biological systems and some mechanisms of its providing, Publishing of Stavropol State Medical University, pp. 3-5 (in Russian)

Gorizontov, P. (1981). Homeostasis, its mechanisms and significance. Meditsina, 1981, pp. 5-28

Kotecki, P. (2018). 10 countries at risk of becoming demographic time bombs. Business insider, Aug. 8, 2018, (https://www.businessinsider.com. $\mathrm{au} / 10$-countries-at-risk-of-becoming-demographic-time-bombs-2018-8)

"Homeostasis" - Meriam-Webster Dictionary (https://www.merriam-webster.com)

Census of the Population and the Housing Stock, 2011 (https://www.nsi.bg) 